\title{
Morbidity and Mortality Associated with Community used Herbal (sagwa)use in Children with Acute Gastroenteritis in Diyala Governorate
}

Ali M Shukur $(\mathrm{MBChB})^{1}$, Jalil I Alezzi (FICMS, DCH) ${ }^{2}$ and Talib J Kadhim (MSc, $\mathrm{PhD})^{3}$

\begin{abstract}
Background: Gastroenteritis causes around (28\%) of all mortalities among children less than $5 \mathrm{yr}$ old. In our country herbal use (called sagwa in Iraq) is one of line of treatment of gastroenteritis mostly in the rural areas.

Objective: To determine the morbidity and mortality of herbal use in acute gastroenteritis in children.

Patients and Methods: Two hundred patients involved in a prospective case control study conducted in the Al-Batool Pediatrics, Obstetrics and Gynecology Teaching Hospital, Diyala, Iraq, during a period of six months from August 2017 to February 2018.

Results: There is significant association of sagwa use with the rural residency $81(81 \%)$, mother education level 57(57\%) illiterate mother), the order of the child in the family 13(13\%)1st child; the least), diarrhea complications (regarding central nervous system 43(43\%), cardiac 58(58\%), renal $49(49 \%)$ and metabolic $83(83 \%)$, hospital stay and condition deterioration and the mortality rate was $9(9 \%)$ in sagwa group .Sagwa toxicity is positively proportional to the number of doses $57(57 \%)$ in 3rd dose \& more) given to children and grandmothers $66(66 \%)$ were the principle person who decided to use sagwa in children with diarrhea. The chemical analysis was done in (10) samples only which revealed that heavy metal like lead, cadmium and mercury; that exceed the permissible level.
\end{abstract}

Conclusion: There is significant morbidity and mortality caused by (sagwa) use in children with acute gastroenteritis.

Keywords: Gastroenteritis, Herbalism, Sagwa poisoning, Children.

Corresponding Author: dr.alimansoor1973@gmail.com

Received: $27^{\text {th }}$ May 2019

Accepted: $10^{\text {th }}$ June 2019

DOI:https://doi.org/10.26505/DJM.17024690527

\section{Introduction}

\footnotetext{
${ }^{1,2}$ College of Medicine- Diyala University - Iraq

${ }^{3}$ College of Veterinary- Diyala University - Iraq.
}

Acute gastroenteritis (AGE) is common in children below 5 years old which last less than two weeks [1]. AGE may be infectious or non-infectious [2]. Many factors affecting the morbidity and mortality of the GE like antibiotics abuse, but the herbal (sagwa) use 
Morbidity and Mortality Associated with Community used Herbal (sagwa)use in Children with Acute

Gastroenteritis in Diyala Governorate

appears to be one of significant factor in our community [3]. The use of herbal products and supplements has increased over the last three decades with at least $80 \%$ of people worldwide depend on them. Many of these herbs are still unlicensed as well as their use is not monitored [4-7].

The potential herbal toxicity may include: Hepatotoxic, Neurotoxic, Nephrotoxic and Cardiotoxicity [8-13]. In Africa, up to $80 \%$ of the people use traditional medicine as herbal preparations for primary health problems, and in China, they account $30-50 \%$ of all medicinal consumption [14]. Many influences such as gender, age, education, ethnicity and social class have important relationship with prevalence of herbal use [15]. The use of herbs is a risky habit because these substances have a lot of harmful actions causing toxicity which may be lethal. Sagwa is one of these substances used to treat diarrhea in children in our country. Insufficient information about their mode of action; adverse reactions, contraindications, and interactions with existing conventional medications are inevitably hazardous $[16,17]$. Herbal remedies are seen by some as preferred treatment as medicines industrially prepared [18]. This study was conducted to determine the morbidity and mortality of herbals use in acute gastroenteritis in children and associated factors.

\section{Patients and Methods}

Study setting and Sample size: This is a prospective case control study conducted in the Al-Batool Pediatrics, Obstetrics and Gynecology Teaching Hospital, Diyala, Iraq, during a period of six months from August 2017 to February 2018. The sample size was calculated using the Epi Info program, version 7.1.0.6 (CDC, Atlanta, GA, USA).

In line with previous studies, we used Twosided confidence level $=95 \%$, power $=80 \%$, ratio of controls to cases $=1$; percent of controls exposed $=15 \%$; odds ratio $=3$. Accordingly, the sample size was calculated as 170 (85 cases and 85 control). Adding $20 \%$ for potential dropouts, we recruited 200 (100 cases and 100 controls) patients to avoid the effects of defaulters confounding the results: $\quad \mathrm{n}_{\mathrm{o}}=\frac{\mathrm{Z}^{2} \mathrm{pq}}{\mathrm{e}^{2}}$

-e is the desired level of precision (i.e. the margin of error)

$-p$ is the (estimated) proportion of the population which has the attribute in question.

$-\mathrm{q}$ is $1-\mathrm{p}$.

\begin{tabular}{|c|c|}
\hline Desired confidence level & z-score \\
\hline \hline $80 \%$ & 1.28 \\
\hline $85 \%$ & 1.44 \\
\hline $90 \%$ & 1.65 \\
\hline $95 \%$ & 1.96 \\
\hline $99 \%$ & 2.58 \\
\hline \hline
\end{tabular}


The study population comprised 200 patients aged (6-59) months, one hundred of them were presented to the hospital with severe GE treated by family with herbals (case group, male $=51(51 \%)$, female $=$ $49(49 \%)$ and the other hundred patients presented to hospital due to severe GE not treated by herbals (control group, male $=$ $53(53 \%)$, female $=47(47 \%)$.

Inclusion criteria for cases children under five years old with sagwa administration and their outcome whether improved, deteriorated or dead; and the control with severe and complicated GE without herbal administration were all included.

Exclusion criteria: any child with mild and moderate GE, chronically ill child and other causes of severe dehydration like metabolic disease and drug toxicity etc. were excluded.

Data were collected by questionnaire form $\&$ information taken from mothers or caregivers including: The patient name, age in months, gender, weight and residence (classified into rural and urban areas), number and order of children in family, educational level of parents (divided into Illiterate, primary, secondary school and higher education) and type of feeding whether breast, bottle or both feeding. Herb Information includes; why and who decide \& encourage to give the herbs (mother, grandmother), the dose times of herbs, is the deterioration appeared in 1st dose or more? Reason made family to use the herbs (social, financial, no response to medicals and no confidence to medicals.
General patient condition and the need for urgent interference as ER, RCU, the treatment needed as CPR, lifesaving drugs, condition of follow up; (Deterioration, improvement, no change, dead), days of hospitalization and the condition on discharge whether improved or died.

Laboratory Methods: $(5 \mathrm{cc})$ of blood are taken from the patient for investigations according to patient's clinical presentations and consider what tests are needed to determine the clinical effects of sagwa which lead to patient's deterioration; laboratory investigations carried on included:

-Complete Blood Count, serum electrolytes (Na+, K+, and Cl-), RBS, hs.CRP, G.U.E, G.S.E, renal function test and liver function test.

Other diagnostic tools are:

- ECG electrocardiography done to patients with cardiac manifestations.

- C.T scan or MRI magnetic resonant imaging done for some patients with neurotoxic manifestations.

- Lumbar Puncture LP was done to exclude CNS infection when it was indicated.

- Ten samples of brought sagwa that collected from the relative of the patient are sent for heavy metal detection by Atomic Absorption Spectroscopy (AAS) which is a technique for measuring the concentration of various elements in the sample.

These samples were given by the segwer (herbalist) for the child who is mostly brought by his mother or grandmother for management of diarrhea, which were prepared at segwer house, sagwa dissolved in 
Morbidity and Mortality Associated with Community used Herbal (sagwa)use in Children with Acute

Gastroenteritis in Diyala Governorate

unknown volume of water and the first an inexact dose ranging from one to two teaspoonful of powder in half glass of water, given to the child at segwer's home. Then more doses to be continued by the relative of the child at home.

The analysis of Sagwa contents: The powdered samples were parched in an oven at $60^{\circ} \mathrm{C}$ for four hours and kept in a drying and an air-tight pot at room temperature for about 10 days. The dried samples separately packed in clean plastic containers, other nonpowdered samples were powdered, filtered and stored in plastic; each sample was analyzed in duplicate.

\section{Statistical analysis}

Analysis of data is carreid out using the available statistical package of SPSS-24 ( Statistical Packages for Social SciencesVersion 24).Data were presented in simple measures of frequency, percentage,mean,standard deviation, and range (minimum-maximum values).

The significance of different percentages (qualitative data )were tested using Pearson Chi-square test $\left(\mathrm{x}^{2}\right.$-test)with application of Yate's correction or Fisher Exact test whenever applicable.Statistical significance was considered whenever the $\mathrm{P}$ value is equal or less than $(0.05)$.

\section{Results}

Table (1) showed the demographic characteristics of children in both groups involved in the study.

Table (2) showed the distribution of social and anthropometric characteristics for both groups involved in the study. There was a highly significant association between the days of diarrhea as a chief complaint and sagwa group $(\mathrm{p}=0.0001)$ where the more days of diarrhea exists the more risk of sagwa use.

Table (3) showed the relationship of clinical characteristics and complications of GE both groups where vomiting and dehydration as well as CNS complications are more common in sagwa group.

Table (4) showed, why and who decide to give sagwa, and given to siblings before and drug used, where the grandmothers who were decided to give the sagwa in 66(66.0\%) and the most apparent cause was "Influence of others" in 33(33\%).

Table (5) The deterioration of clinical condition with sagwa doses was noted more after the third and more doses 57(57\%), while it was $32(32 \%)$ with 2 nd dose and more less $11.0 \%$ with the first dose.

Table (6) showed the clinical outcome from admission to hospital, follow up and discharge.

Table (7) showed the chemical contents and heavy metal concentration in $(\mathrm{mg} / \mathrm{kg})$ in ten sagwa samples. 
Morbidity and Mortality Associated with Community used Herbal (sagwa)use in Children with Acute

Table (1): the demographic characteristics of children in both groups

\begin{tabular}{|c|c|c|c|c|c|}
\hline \multirow[t]{2}{*}{ Variable } & \multicolumn{2}{|c|}{ Sagwa(herb) } & \multicolumn{2}{|c|}{ Control } & \multirow[t]{2}{*}{ P value } \\
\hline & No. & $\%$ & No. & $\%$ & \\
\hline \multicolumn{5}{|l|}{ Residence } & \multirow{4}{*}{$0.024 *$} \\
\hline Urban & 19 & 19.0 & 33 & 33.0 & \\
\hline Rural & 81 & 81.0 & 67 & 67.0 & \\
\hline Total & 100 & 100.0 & 100 & 100.0 & \\
\hline \multicolumn{5}{|l|}{ Children age } & \multirow[t]{5}{*}{0.512} \\
\hline (6-11) months & 69 & 69.0 & 70 & 70.0 & \\
\hline (12-23) months & 25 & 25.0 & 23 & 23.0 & \\
\hline (24-59) months & 6 & 6.0 & 7 & 7.0 & \\
\hline Total & 100 & 100.0 & 100 & 100.0 & \\
\hline \multicolumn{5}{|l|}{ Children gender } & \multirow[t]{4}{*}{0.777} \\
\hline Male & 49 & 49.0 & 47 & 47.0 & \\
\hline Female & 51 & 51.0 & 53 & 53.0 & \\
\hline Total & 100 & 100.0 & 100 & 100.0 & \\
\hline
\end{tabular}

* Significant Chi-square test.

Table (2): Distribution of social \& anthropometrics for both groups

\begin{tabular}{|c|c|c|c|c|c|}
\hline \multirow[t]{2}{*}{ Variable } & \multicolumn{2}{|c|}{ Sagwa(herb) } & \multicolumn{2}{|c|}{ control } & \multirow[t]{2}{*}{$P$ value } \\
\hline & No. & $\%$ & No. & $\%$ & \\
\hline \multicolumn{5}{|l|}{ Weight (kg) } & \multirow[t]{6}{*}{0.892} \\
\hline$<4.0$ & 7 & 7.0 & 6 & 6.0 & \\
\hline $4.0-6.0$ & 21 & 21.0 & 32 & 32.0 & \\
\hline$\overline{77.0-9.0}$ & 43 & 43.0 & 38 & 38.0 & \\
\hline $10.0-12.0$ & 20 & 20.0 & 18 & 18.0 & \\
\hline$>12.0$ & 9 & 9.0 & 6 & 6.0 & \\
\hline \multicolumn{5}{|l|}{ Mother education } & \multirow[t]{5}{*}{$0.0001 *$} \\
\hline Illiterate & $\overline{c 57}$ & 57.0 & 26 & 26.0 & \\
\hline Primary & 33 & 33.0 & 43 & 43.0 & \\
\hline Secondary & 7 & 7.0 & 25 & 25.0 & \\
\hline College \& Higher & 3 & 3.0 & 6 & 6.0 & \\
\hline
\end{tabular}


Morbidity and Mortality Associated with Community used Herbal (sagwa)use in Children with Acute

\begin{tabular}{|c|c|c|c|c|c|}
\hline \multicolumn{5}{|l|}{ Father education } & \multirow[t]{5}{*}{0.246} \\
\hline Illiterate & 32 & 32.0 & 25 & 25.0 & \\
\hline Primary & 46 & 46.0 & 40 & 40.0 & \\
\hline Secondary & 15 & 15.0 & 24 & 24.0 & \\
\hline College\&Higher & 7 & 7.0 & 11 & 11.0 & \\
\hline \multicolumn{5}{|c|}{ Order of kid in the family } & \multirow[t]{6}{*}{$0.040 *^{\mathrm{S}}$} \\
\hline First & 13 & 13.0 & 26 & 26.0 & \\
\hline Second & 19 & 19.0 & 23 & 23.0 & \\
\hline Third & 19 & 19.0 & 19 & 19.0 & \\
\hline Fourth & 20 & 20.0 & 18 & 18.0 & \\
\hline Fifth \& later & 29 & 29.0 & 14 & 14.0 & \\
\hline \multicolumn{5}{|l|}{ Type of feeding } & \multirow[t]{4}{*}{0.524} \\
\hline Breast & 16 & 16.0 & 19 & 19.0 & \\
\hline Bottle & 53 & 53.0 & 57 & "57.0 & \\
\hline Mixed & 31 & 31.0 & 24 & 24.0 & \\
\hline
\end{tabular}

* Significant, Chi-square test

Table (3): Relationship of clinical characteristics and complications of both groups

\begin{tabular}{|c|c|c|c|c|c|}
\hline \multirow[t]{2}{*}{ Variable } & \multicolumn{2}{|c|}{ Sagwa(herb) } & \multicolumn{2}{|c|}{ control } & \multirow[t]{2}{*}{ P value } \\
\hline & No. & $\%$ & No. & $\%$ & \\
\hline \multicolumn{5}{|c|}{ Vomiting after $3^{\text {rd }}$ day of sagwa intake } & \multirow[t]{4}{*}{$0.001 *$} \\
\hline Yes & 84 & 84.0 & 33 & 33.0 & \\
\hline No & 16 & 16.0 & 67 & 67.0 & \\
\hline Total & 100 & 100.0 & 100 & 100.0 & \\
\hline \multicolumn{5}{|c|}{ Duration of dehydration } & \multirow[t]{4}{*}{$0.001 *$} \\
\hline Less than $48 \mathrm{hr}$ & 35 & 35.0 & 97 & 97.0 & \\
\hline More than $48 \mathrm{hr}$. & 65 & 65.0 & 3 & 3.0 & \\
\hline Total & 100 & 100.0 & 100 & 100.0 & \\
\hline \multicolumn{5}{|c|}{ Respiratory distress } & \multirow[t]{4}{*}{0.179} \\
\hline Yes & 10 & 10.0 & 5 & 5.0 & \\
\hline No & 90 & 90.0 & 95 & 95.0 & \\
\hline Total & 100 & 100.0 & 100 & 100.0 & \\
\hline \multicolumn{5}{|l|}{$\overline{\mathrm{CNS}}$} & $0.0001 *$ \\
\hline
\end{tabular}


Morbidity and Mortality Associated with Community used Herbal (sagwa)use in Children with Acute

\begin{tabular}{|c|c|c|c|c|c|}
\hline Yes & 43 & 43.0 & 10 & 10.0 & \\
\hline No & 57 & 57.0 & 90 & 90.0 & \\
\hline Total & 100 & 100.0 & 100 & 100.0 & \\
\hline \multicolumn{5}{|c|}{ Cyanosis } & \multirow[t]{4}{*}{0.179} \\
\hline Yes & 10 & 10.0 & 5 & 5.0 & \\
\hline No & 90 & 90.0 & 95 & 95.0 & \\
\hline Total & 100 & 100.0 & 100 & 100.0 & \\
\hline \multicolumn{5}{|c|}{ Arrhythmia } & \multirow[t]{4}{*}{$0.001 *$} \\
\hline Yes & 58 & 58.0 & 24 & 24.0 & \\
\hline No & 42 & 42.0 & 76 & 76.0 & \\
\hline Total & 100 & 100.0 & 100 & 100.0 & \\
\hline \multicolumn{5}{|c|}{ Acidosis } & \multirow[t]{4}{*}{$0.001 *$} \\
\hline Yes & 83 & 83.0 & 37 & 37.0 & \\
\hline No & 17 & 17.0 & 63 & 63.0 & \\
\hline Total & 100 & 100.0 & 100 & 100.0 & \\
\hline \multicolumn{5}{|c|}{ Oliguria \& anuria } & \multirow[t]{4}{*}{$0.0001 *$} \\
\hline Yes & 49 & 49.0 & 5 & 5.0 & \\
\hline No & 51 & 51.0 & 95 & 95.0 & \\
\hline Total & 100 & 100.0 & 100 & 100.0 & \\
\hline
\end{tabular}

* Significant, Chi square test

Table (4): Why and who decide to give sagwa, previous use to siblings and drug used

\begin{tabular}{|c|c|c|}
\hline \multirow[t]{2}{*}{ Variable } & \multicolumn{2}{|c|}{ Sagwa (herb) } \\
\hline & No. & $\%$ \\
\hline \multicolumn{3}{|l|}{ Who decide } \\
\hline Mother & 21 & 21.0 \\
\hline Father & 4 & 4.0 \\
\hline Grandmother & 66 & 66.0 \\
\hline Grandfather & 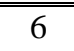 & 6.0 \\
\hline Others & 3 & 3.0 \\
\hline Total & 100 & 100.0 \\
\hline \multicolumn{3}{|l|}{ Why decide } \\
\hline No trust in drugs & 22 & 22.0 \\
\hline No response to drugs & 21 & 21.0 \\
\hline Belief of herbs safety & 9 & 9.0 \\
\hline
\end{tabular}


Morbidity and Mortality Associated with Community used Herbal (sagwa)use in Children with Acute

\begin{tabular}{||l||c||c|}
\hline Available \& cheaper & 15 & 15.0 \\
\hline \hline Influence of others & 33 & 33.0 \\
\hline \hline Total & 100 & 100.0 \\
\hline
\end{tabular}

Table (5): Deterioration of child condition with sagwa dosing

\begin{tabular}{||l|c|c||}
\hline \multicolumn{1}{|c|}{ Variable } & \multicolumn{2}{c||}{ Sagwa (herb) } \\
\cline { 2 - 3 } & No. & $\%$ \\
\hline \hline Deterioration after dosing & 11 & 11.0 \\
\hline \hline $1^{\text {st }}$ dose & 32 & 32.0 \\
\hline \hline $2^{\text {nd }}$ dose & 57 & 57.0 \\
\hline \hline $3^{\text {rd }}$ dose \& more & 100 & 100.0 \\
\hline \hline Total & \\
\hline \hline
\end{tabular}

Table (6): The clinical outcome from admission to hospital, follow up and discharge in both groups

\begin{tabular}{|c|c|c|c|c|c|}
\hline \multirow[t]{2}{*}{ Variable } & \multicolumn{2}{|c|}{$\begin{array}{l}\text { Sagwa(herb) } \\
\text { group }\end{array}$} & \multicolumn{2}{|c|}{$\overline{~ C o n t r o l ~ g r o u p ~}$} & \multirow[t]{2}{*}{ P value } \\
\hline & No. & $\%$ & No. & $\%$ & \\
\hline \multicolumn{5}{|l|}{ Need urgent } & \multirow[t]{4}{*}{$0.001 *$} \\
\hline ER \& RCU & 13 & 13.0 & 1 & 1.0 & \\
\hline Only ER & 87 & 87.0 & 99 & 99.0 & \\
\hline Total & 100 & 100.0 & 100 & 100.0 & \\
\hline \multicolumn{5}{|c|}{ Condition during hospitalization \& follow up } & \multirow[t]{4}{*}{$0.0001 *$} \\
\hline Deteriorated & 77 & 77.0 & 14 & 14.0 & \\
\hline Improved & 23 & 23.0 & 86 & 86.0 & \\
\hline Total & 100 & 100.0 & 100 & 100.0 & \\
\hline \multicolumn{5}{|c|}{ Days of hospitalization } & \multirow[t]{5}{*}{$0.0001^{*}$} \\
\hline (1-3 days) & 9 & 9.0 & 39 & 39.0 & \\
\hline (4-6 days) & 14 & 14.0 & 50 & 50.0 & \\
\hline 7 days \& more & 77 & 77.0 & 11 & 11.0 & \\
\hline Total & 100 & 100.0 & 100 & 100.0 & \\
\hline \multicolumn{5}{|l|}{ On discharge } & \multirow[t]{5}{*}{$0.001 *$} \\
\hline Death & 9 & 9.0 & 1 & 1.0 & \\
\hline Improved & 68 & 68.0 & 96 & 96.0 & \\
\hline Referred & 23 & 23.0 & 3 & 3.0 & \\
\hline Total & 100 & 100.0 & 100 & 100.0 & \\
\hline
\end{tabular}

* Significant, Chi-square test 
Morbidity and Mortality Associated with Community used Herbal (sagwa)use in Children with Acute

Table (7): the chemical contents and heavy metal concentration in $(\mathrm{mg} / \mathrm{kg})$ in ten sagwa samples

\begin{tabular}{|l||c||c|c||c||c||}
\hline \multirow{2}{*}{ No. } & \multirow{2}{*}{$\begin{array}{c}\text { Herb } \\
\text { samples } \\
(\text { Sagwa) }\end{array}$} & $\begin{array}{c}\text { Lead } \\
(\mathrm{Pb})\end{array}$ & $\begin{array}{c}\text { Mercury } \\
(\mathrm{Hg})\end{array}$ & $\begin{array}{c}\text { Cadmium } \\
(\mathrm{Cd})\end{array}$ & $\begin{array}{c}\text { Arsenic } \\
(\mathrm{As})\end{array}$ \\
\hline \hline 1 & $\mathrm{~A}$ & $\underline{13.3}$ & 0.1 & $\underline{0.32}$ & 0.01 \\
\hline \hline 2 & $\mathrm{~B}$ & $\underline{11.7}$ & 0.01 & 0.13 & 0.2 \\
\hline \hline 3 & $\mathrm{C}$ & $\underline{15.5}$ & 0.01 & $\underline{0.5}$ & 0.1 \\
\hline \hline 4 & $\mathrm{D}$ & $\underline{14.1}$ & $\underline{0.3}$ & 0.23 & 0.03 \\
\hline 5 & $\mathrm{E}$ & $\underline{12.6}$ & 0.05 & $\underline{0.7}$ & 0.2 \\
\hline \hline 6 & $\mathrm{~F}$ & $\underline{10.7}$ & 0.02 & $\underline{0.66}$ & 0.0 \\
\hline \hline 7 & G & $\underline{14.5}$ & 0.033 & 0.01 & 0.02 \\
\hline \hline 8 & H & $\underline{12.5}$ & 0.021 & 0.1 & 0.05 \\
\hline \hline 9 & I & 8.0 & 0.13 & $\underline{0.33}$ & 0.01 \\
\hline \hline 10 & J & 5.0 & 0.15 & $\underline{0.77}$ & 0.2 \\
\hline
\end{tabular}

Table of Permissible limits, PL of heavy metals

\begin{tabular}{|c||c||c||c||c||c||}
\hline $\begin{array}{c}\text { Permissible limits } \\
\mathbf{m g} / \mathbf{k g}\end{array}$ & $\begin{array}{c}\text { Lead } \\
\mathbf{P b}\end{array}$ & $\begin{array}{c}\text { Mercury } \\
\mathbf{H g}\end{array}$ & $\begin{array}{c}\text { Cadmium } \\
\mathbf{C d}\end{array}$ & $\begin{array}{c}\text { Arsenic } \\
\text { As }\end{array}$ & Ref. \\
\hline \hline WHO & 10 & 0.2 & 0.3 & 0.5 & $(20)$ \\
\hline \hline Euro-Pharma-copoeia & & & & & \\
& 5 & 0.1 & 0.5 & 0.5 & $(21)$ \\
\hline
\end{tabular}

\section{Discussion}

Sagwa use is a common problem in our community especially in rural areas where most of admitted patients were from the rural area $81(81.0 \%)$ since mothers from these areas are more likely to use the sagwa due to the low level of their education, low socioeconomic status of the families and easy accessibility to sagwa. moreover, thinking of the sagwa is safer than the medications as well as difficulty access the health centers [3, 22], but this in contrast to that found in Turkey [23, 24]. Probably due to different sampling techniques.
Regarding age groups, there is no significance difference between cases and control, but both groups showed high percentage $69(69.0 \%), 70(70.0 \%)$ of diseased children in age group (6-11 months), and nearly the same thing regarding the gender for both groups, which is in contrast to that found in Germany [25].since both groups are from the same community.

No statistical significance difference obtained in relation to gender where males and females were affected almost equally similarly found by many previous studies in Iraq [3] and in Germany [25]. 
Regarding the social and anthropometric measures there is significant association with the order of the child in the family in sagwa group than in the control group, where the fifth \& later children are more likely to be given sagwa, probably due to previous mothers experience with sagwa and advice from other family members. As well as the heavy burden on the mother make her seeking advice to stop diarrhoea and may be the delayed recovery from the illness. The health education plays major role in preventing the use of sagwa in these children. Sagwa intake was more common in children of low education level or illiterate mothers and primary school mother, similar results was found in Iraq by [26, 27, 28]. Since illiterate mother has no proper ideas about treating diarrheal disease and easily misled by others to use sagwa, and she cannot appreciate the biohazards of sagwa to their children.

The other parameters like body weight, father education and type of feeding, have no significant association with sagwa intake group in comparison to control group.

Regarding clinical features of the both groups, there was significant association with vomiting after third day of illness in sagwa group $84(84.0 \%)$, whereas in control group it was $33(33.0 \%)$, since sagwa cause gastric irritation and vomiting as side effect which affect the regeneration of gastric mucosa.

Dehydration present for more than forty eight hours in sagwa group than control group; due to delayed presentation to the hospital as well as side effects of sagwa. This is in agreement with previous studies in South Africa [29, 30, 31].

The complications of AGE with sagwa, the CNS and renal complications have a high significant association in comparison to control group $\quad(p=0.0001)$ Regarding arrhythmias (bradycardia, sinus tachycardia, ventricular ectopics, ventricular tachycardia, and ventricular fibrillation and heart block) and acidosis both of which have significant association with sagwa $(\mathrm{p}=0.001)$ in sagwa group; in comparison to control group, this is mostly related to the toxic effects of the sagwa; (neurotoxicity, nephrotoxicity and cardiotoxicity). There are many factors which increase the toxicity of sagwa which include the following; most of them do not meet the standards of good manufacturing practices, concentrations of active ingredients are unpredictable, their labeling is inadequate, wrong dose or diagnosis, herb contamination, debasement and interaction by herb to herb or to drug. Our findings are similar to previous studies conducted in Iran, South Africa and USA [26, 29, 32]. The grandmothers had great impact on the use of sagwa in affected children. The decision to use sagwa may be due to the following influence of others, no trust in drugs and no response to drugs as noted in South Africa [30]. While in other studies they didn't find any significant justification to the sagwa use in Iraq and South Africa [27, 33, 34] .The deterioration of child condition, is worse following the third dose and more of sagwa intake, this is probably related to dose- 
Morbidity and Mortality Associated with Community used Herbal (sagwa)use in Children with Acute

Gastroenteritis in Diyala Governorate

toxicity which is in agreement with previous studies in Nigeria and S. Africa [30, 35].

The clinical consequences from hospitalization, follow up till discharge, where most of children with sagwa necessitate emergency room visit as well as emergency room and respiratory care unit in comparison to control group; this is mostly due to detrimental effect of sagwa use. The child condition during hospitalization was deteriorated in $77(77.0 \%)$ of children in sagwa group; while only $14(14.0 \%)$ control group was deteriorated; this led to more days of hospitalization and its cost and burden on the hospital which is in agreement with previous study in Iran [32]. In regard to the condition on discharging, we found that 96(96.0\%) of control group improved but only $68(68.0 \%)$ in sagwa group, and $23(23.0 \%)$ in sagwa group was referred to another centers for further management, while only $3(3.0 \%)$ in control group was referred. Unfortunately $9(9.0 \%)$ of children died in sagwa group while only $1(1.0 \%)$ in control group due to the toxic effect of the sagwa, which is in agreement with previous studies Iran and S. Africa[29, 32].

Regarding the constituents of sagwa, unfortunately chemical analysis was carried out in [10] samples of sagwa only due to similarity of the taken samples, which was done by Atomic Absorption Spectroscopy, where lead contents exceeded the permissible level (PL) in [8] samples, cadmium exceeded the PL in [6] samples, while the mercury exceeded PL only in [1] sample, but arsenic not found in any of analyzed samples. The source of these heavy metals could be by environmental pollution of the soil where the root of the herbs or by insecticides or pesticides and fertilizers in the agricultural fields, or contamination during preparation or processing of the sagwa by the herbalist. These results agreed with studies in Iran, Pakistan and Emirates [36,37, 38].

\section{Conclusions}

There is significant morbidity and mortality caused by (sagwa) use in children with acute gastroenteritis:

1-There is significant association of sagwa use with the residency, mother education level and the order of the child in the family. And grandmothers are the principle person who decided to use sagwa.

2-There is significant association between sagwa use with appearance of CNS, cardiac, renal and metabolic complications.

3-Sagwa toxicity is positively proportional to the number of doses of sagwa given to children.

4-The hospital stay, condition deterioration and case fatality rate are more significant in sagwa group than control.

5-The chemical analysis revealed that heavy metal like lead, cadmium and mercury; that exceed the permissible limit.

\section{Recommendations}

Regarding the study :Multicenter studies including the health centers and hospitals in the districts should be performed to cover all sagwa poisoning cases and its consequences.

Larger sample size with extended period of study to involve all cases of sagwa poisoning 
Morbidity and Mortality Associated with Community used Herbal (sagwa)use in Children with Acute

Gastroenteritis in Diyala Governorate

as well as the referred and dead cases in the other centers or forensic medicine centers.

Providing a poisoning consultation center in Diyala governorate to facilitate the herbs or sagwa samples screening and for phone contacts management consultation for poisoning cases.

Regarding the poisonous cases and the community:Consider the sagwa poisonings as a police cases need medicolegal documentation.

Community education by employment of media channels, social media's, health messages and mothers' education at health centers during vaccination schedule and involving non-governmental organizations especially to the risks of the sagwa administration and poisoning.

Facilitate phone contacts of the community with the poisoning center in sagwa poisoning cases.

Herb educational courses and training for the herbalists by governmental skilled teams.

Limitation of herbalists' license in the department of herbal Medicine in Iraqi ministry of health to control their work regarding dispersion of herbal products in the community and to decrease their unwanted effects.

Regarding the hospitals and health centers: Informative education of the medical staff in the sagwa poisoning cases.

Documentation and recording all cases of sagwa poisoning and send them to the pharmacovigilance center in the Iraq ministry of health.
Because of the burden of sagwa poisoning cases with significant morbidity and mortality, it is recommended the major hospitals in the governorate to set applicable guidelines to manage sagwa poisoning cases.

\section{References}

[1]Robert M. Kliegman, Bonita F. Stanton, Nina F. Schor, Joseph W. St Geme III, Richard E. Behrman (Editor Emeritus), Nelson Textbook of Pediatrics, Twentieth Edition, chapter 18: p 1761.

[2]De Hostos EL, Choy RKM, Nguyen T.: Developing novel antisecretory drugs to treat infectious diarrhoea. Future Medical Chemistry 2011; 3(10):1317-1325. [3]Manal M. Younus, Noor K. Ali, Hadeel R. Abdulqader; "Traditional Medicine in Iraq, is it still a source of serious adverse events?" A documentation of serious adverse events of Sagwa among infants in Iraqi Pediatric Hospitals, Iraqi New Medical Journal July 2017; 3 (2).

[4]Mukherjee, P.W. (2002). Quality Control of Herbal Drugs: An Approach to Evaluation of Botanicals. New Delhi, India: Business Horizons Publishers) Page Count: 700.ch.1, pp.33.

[5]Bodeker, C., Bodeker, G., Ong, C. K., Grundy, C. K., Burford, G., and Shein, K. (2005). WHO, Global Atlas of Traditional, Complementary and Alternative Medicine. Geneva, Switzerland: Sec.B. pp.34.

[6]Bandaranayake Wickramasinghe. M. (2006). "Quality control, screening, toxicity, and regulation of herbal drugs". Modern Phytomedicine. Turning Medicinal Plants into Drugs Edited by Ahmad I., Aqil F. and 
Morbidity and Mortality Associated with Community used Herbal (sagwa)use in Children with Acute

Gastroenteritis in Diyala Governorate

Owais M., editors. (Weinheim: Wiley-VCH GmbH \& Co. KGaA), 25-57; .ch2.

[7]Akerele, O. (1993). Nature's medicinal bounty: Don't throw it away. World Health Forum 14, 390-395.

[8]B. Saad, H. Azaizeh, G. Abu-Hijleh, and O. Said, (2006), "Safety of traditional Arab herbal medicine," Evidence-Based Complementary and Alternative Medicine, vol. 3, no. 4, pp. 433-439.

[9]El Nahhal Y. (2004) "Contamination and safety status of plant and food in Arab countries". Applied Science Journal; 4: 411 7.

[10]Chaudhary, G., Goyal, S., Poonia, P., 2010. Lawsonia inermis Linnaeus: "A phytopharmacological review". International Journal of Pharmacology Science and Drug Research. 2, 91-98.

[11]Atawodi, S.E., A. C. ENE, A.C., Fatihu, M.Y., 2013. "Toxic effects of sub-chronic administration of chloroform extract of Artemisia maciverae linn on the kidney of Swiss albino rats". International Journal of Biochemistry. 3, 119128. British Journal of Pharmaceutical Research 4(15).

[12]Blackwell WH, ed. Englewood Cliffs, NJ: Prentice - Hall, 1990. 48: 406-412.

[13]Dart RC. "Introduction to plants. In Medical toxicology", 3rd ed., pp. $1665-71$. Dart RC, ed. Philadelphia, PA: Lippincott, Williams, and Watkins, 2003.

[14]WHO World Health Organization (1998)."Regulatory Situation of Herbal Medicines". A Worldwide Review (WHO/trm/98.1) Geneva: 1998.ch.2, pp.4. [15]Bishop F. L.; Lewith G. T. (March
2010). "Who Uses CAM? A Narrative Review of Demographic Characteristics and Health Factors Associated with.CAM.Use". Evid Based Complementary and Alternative Medicine. 7 (1):11, 28.

[16]Complementary, and Alternative Medicine in United States" by American Public, Board on Health Promotion, and Disease Prevention, 2007. Ch.2, pp.34.

[17]National Center for Complementary and Integrative Health "More Than One-Third of U.S. Adults Use Complementary and Alternative Medicine Press release", 27 May 2004.

[18]James A. Duke (December 1999 January 2000). "Returning to our Medicinal Roots". Mother Earth News: 26-33.

[19]Bartlett, J. et al. (2001). Organizational Research: Determining Appropriate Sample Size in Survey ,Information Technology, Learning, and Performance Journal, Vol. 19 (1).

[20]World Health Organization (WHO). WHO guidelines for assessing quality of herbal medicines with reference to contaminants and residue. Geneva: WHO; 2007.ch.3, pp.19, ch.4, pp.423.

[21]Herbal drugs. Monograph 1433. Pharmeuropa 2008; 20(2):302-3.

[22]H.A.L. Catublas; "Knowledge, attitudes and practices in the use of herbal medicine: the case of urban and rural mothers in the Philippines"; Mahidol University Journal of Pharmaceutical Sciences, vol.43, pp.1-16 No.1, July-September 2016.

[23]Sefa Akbulut; "Differences in the Traditional Use of Wild Plants between Rural 
Morbidity and Mortality Associated with Community used Herbal (sagwa)use in Children with Acute

Gastroenteritis in Diyala Governorate

and Urban Areas: The Sample of Adana".Article in Studies on Ethno-Medicine 9(2):141-150.

[24]Jon Adams, David Sibbritt, and Chi-Wai Lui; "The urban-rural divide in complementary and alternative medicine use": a longitudinal study of 10,638 women, DOI: 10.1186/1472-6882-11-2.

[25]Yong Du, Ingrid-Katharina Wolf1, Wanli Zhuang, Stefanie Bodemann, Werner Knöss and Hildtraud Knopf " Use of herbal medicinal products among children and adolescents in Germany" 2014. Du et al. BMC Complementary and Alternative Medicine 2014, 14:218.

[26]Wayne R. Snod Grass; "Herbal products: Risks and benefits of use in children" Volume 62, Issue 10, October 2001, 724-737. [27]Narjes Chyad Abdulzahra; "Attitude of Mothers toward Herbal Treatment of Their Children"; college of medicine, university of Kerbala. Karbala Journal Medicine. Vol.5, No.1, Dec, 2012

[28]Justina Sunday Ikoedem, Chinweizu Ejikeme Udobi and Ememobong Gideon Asuquo "The Use of Medicinal Plants in the Treatment of Diarrhoea in Ibibio Land: A Survey" June 2018 with 53 Reads. Microbiology Research Journal 24(1):1-12. [29]Tindimwebwa G, Dambisya YM; "when is it herbal intoxication? A retrospective study of children admitted with herbal intoxication at Umtata General Hospital, South Africa". Cent 2003 Sep-Oct; 49(910):111-4.

[30]Y.M. Dambisya and G. Tindimwebwa "traditional remedies in children around eastern cape, south Africa"; 2003. East African Medical Journal Vol. 80. No. 8:4025.

[31]Die-Kacou H, Kamagate M, Yavo JC, Daubret TH, Diafouka F "Intoxications Par Les Plantes A Abidjan: Difficulties Du Diagnostic Etiologique ET Aspects Ethnobotaniques". Revue Bio-Africa - Nº7 2009, pp. 34-43.

[32]Adel Ghorani-Azam, Samaneh Sepahi, Bamdad Riahi-Zanjani, Anahita Alizadeh Ghamsari, Seyed Ahmad Mohajeri, and Mahdi Balali-Mood." Plant toxins and acute medicinal plant poisoning in children: A systematic literature review" Journal of Research Medical Science. 2018; 23: 26. [33]Matlagolo Mosa Moshabela "Reasons Given by Caregivers For Administering African Herbal Medicines to Children at st Rita's Hospital in Sekhukhune district of Limpopo Province, South Africa".2008.Ch.5, pp.155.

[34]Ban Abdulkhalk Yehea Al-Handh "Herbal Treatment, Usage Frequency, Types and Preferences in Tikrit city, Iraq"2012. Tikrit Journal of Pharmaceutical Sciences 2012 8(2). 290.

[35]Olufunsho Awodele, Kennedy lliya Amagon, So Usman, OoPrecious, "Safety of Herbal Medicines Use: Case Study of Ikorodu Residents in Lagos, Nigeria"2013. Article in BMC Complementary and Alternative Medicine 11(1):117 • November 2011Source: PubMed. Curr Drug Saf. 2014; 9(2):138-44.

[36]P. Ziarati "Determination of Contaminants in Some Iranian Popular 
Herbal Medicines" Ziarati, J Environment

Analytic Toxicol 2012, 2:1. J Environment

Analytic Toxicol 2012, Vol. 2(1): 120.

[37]Rania Dghaim, Safa Al Khatib, Husna

Rasool, and Munawwar Ali Khan

"Determination of Heavy Metals

Concentration in Traditional Herbs

Commonly Consumed in the United Arab

Emirates" Hindawi Publishing Corporation

Journal of Environmental and Public Health

Volume 2015, Article ID 973878, 6 pages.

[38]Bushra Hina, Ghazala Hafeez Rizwani, Huma Shareef and Maryam Ahmed "Atomic absorption spectroscopic analysis of some Pakistani herbal medicinal products used in respiratory tract infections" Pakistan journal of pharmaceutical sciences 25(1):247-53. 